\title{
Seismic Performance Evaluation of a Reinforced Concrete Arch Bridge
}

\author{
Jeena Dangol', Rajan Suwal ${ }^{\mathbf{2}}$ \\ ${ }^{1}$ Structural Engineer, er.xena@gmail.com \\ ${ }^{2}$ Department of Civil Engineering, Pulchhowk Campus, Institute of Engineering, TU, Nepal \\ Corresponding author: rajan_suwal@yahoo.com
}

Received: March 7, 2016 Revised: July 4, 2016 Accepted: July 15, 2016

\begin{abstract}
The entire Himalayan belt including Nepal area, because of its active tectonic movement, is seismically active causing high risk of earthquake in this region. It is important to evaluate the seismic performance of the structures including bridges to identify to what extent they would survive during earthquake. A reinforced concrete two hinged arch bridge located in Chobhar, Nepal has been selected for the research purpose. This paper presents the determination of seismic performance of a reinforced concrete arch bridge under different ground motions. The seismic input was taken as five different earthquake ground motion histories having different $\mathrm{V} / \mathrm{H}$ peak ground acceleration ratio for time history analysis. Displacement capacity of the bridge was determined from pushover analysis. Time history analysis was conducted in two different steps: first only horizontal acceleration was applied and next vertical acceleration was applied in addition to horizontal ground motion. Comparisons were made between the responses of the bridge for these two cases. It was found that inclusion of vertical component of ground motion has negligible effect in variation of longitudinal displacement. However, there was remarkable effect in axial force variation. Significant effect in axial force variation in arch rib was observed as $\mathrm{V} / \mathrm{H}$ ratio increased although the effect in longitudinal displacement with increase in $\mathrm{V} / \mathrm{H}$ ratio was negligible. Moment demand also increased due to high axial force variation because of vertical ground motion.
\end{abstract}

Keywords: Seismic Performance Evaluation, V/H Peak Ground Acceleration Ratio, Vertical Acceleration, Horizontal Acceleration

\section{Introduction}

Since Nepal is located highly seismically vulnerable zone, bridges are likely to damage in severe earthquake if they were not designed properly. It was observed that there was number of bridges which were damaged and collapsed in Nepal and other countries. Wenchuan Earthquake (M8) that occurred in China in 2008 showed extensive damages of nearly 1600 bridges $[1,2]$. Several reinforced concrete and stone masonry arch bridges were damaged in the earthquake and studied $[3,4,5,6,7]$. Cracks are seen in masonry bridge of Bhadrakali-Sinhadarbar road (Tukucha bridge). Damages of bearings and settlements of abutments are seen in the certain bridges of Kathmandu 
valley. To assess the condition of bridges is very important in the case of earthquake. Reinforced Concrete Chobhar arch bridge is taken for research purpose.

Bridge Description: A reinforced concrete two hinged arch bridge located in Chobhar, $9 \mathrm{~km}$ southeast of Kathmandu, Nepal, has been selected for the research purpose. The view of the bridge is shown in Fig. 1. Total length of the bridge is $39.39 \mathrm{~m}$ with an effective length of a span of 38.44 $\mathrm{m}$. Carriageway width is $7.5 \mathrm{~m}$ and clear width of the footpath on either side is $1.0 \mathrm{~m}$, making total width of the bridge as $10.65 \mathrm{~m}$. The overview of bridge is shown in Fig 1 and sectional elevation of the bridge is shown in Fig. 2.

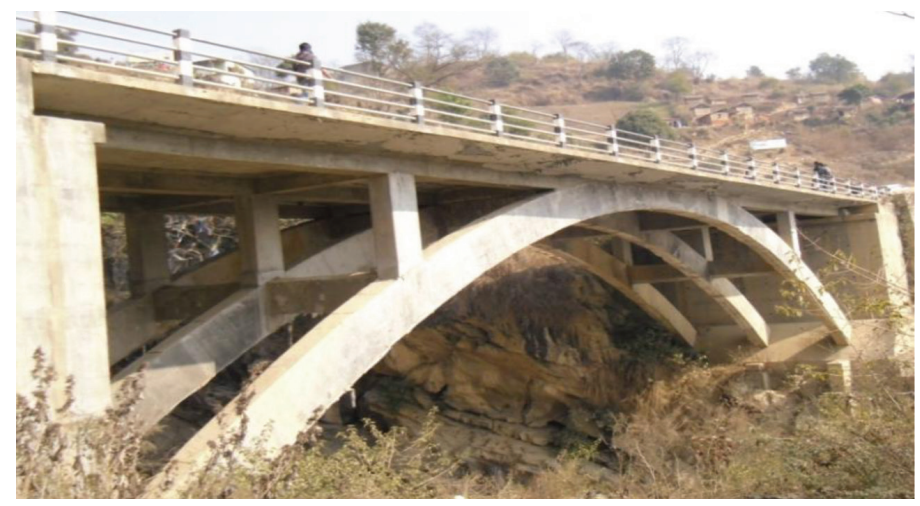

Fig. 1: View of Chobhar Arch Bridge

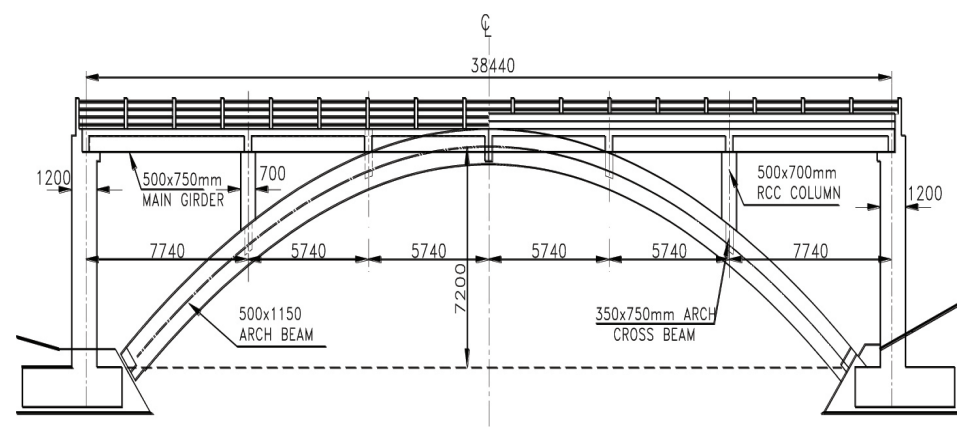

Fig. 2: Sectional Elevation of the Bridge

Bridge Modeling: A three-dimensional finite element model of the study bridge was created using SAP2000 as shown in Fig. 3. The bridge deck was modeled with a four-node plane shell element; girders and columns with beam elements and arch using straight line beam element.

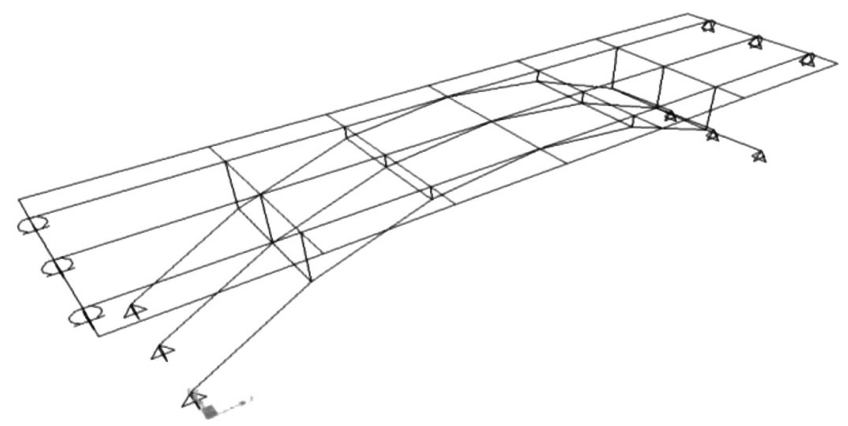

Fig. 3: Finite Element Model of the Bridge 


\section{Analysis and Results}

\section{Modal Analysis}

Modal analysis was used to determine the natural mode shapes and frequencies of a structure during free vibration. The fundamental time period of vibration was found to be $0.358 \mathrm{sec}$.

\section{Non Linear Static Analysis - Pushover Analysis}

In order to obtain the performance of the bridge, pushover analysis was carried out. From the analysis, displacement capacity of the bridge was found to be $60 \mathrm{~mm}$ in longitudinal direction and $170 \mathrm{~mm}$ in transverse direction.

\section{Dynamic Analysis - Time History Analysis}

Linear modal time history analysis was conducted using five different strong ground motions with varying $\mathrm{V} / \mathrm{H}$ ratio. Table 1 list out the ground motion used for the study. The analysis was conducted first considering only horizontal components applied along longitudinal and transverse directions of the bridge. The results have been presented in the Table 2 and 3 below:

Table 1: Ground Motions considered for the Seismic Study

\begin{tabular}{|c|c|c|c|c|c|c|c|}
\hline \multirow{2}{*}{ SN } & \multirow{2}{*}{ Earthquake } & \multirow{2}{*}{ Mw } & \multirow{2}{*}{ Station } & \multicolumn{3}{|c|}{ PGA $(\mathrm{g})$} & \multirow{2}{*}{ V/H } \\
\cline { 5 - 7 } & & & $\mathrm{X}$ & $\mathrm{Y}$ & $\mathrm{UP}$ & \\
\hline 1 & Northridge (1994) & 6.7 & Arleta-Fire & 0.345 & 0.308 & 0.552 & 1.79 \\
\hline 2 & Landers (1992) & 7.3 & Lucrene & 0.73 & 0.79 & 0.82 & 1.04 \\
\hline 3 & Loma Prieta (1989) & 7.0 & Corralitos & 0.644 & 0.48 & 0.455 & 0.95 \\
\hline 4 & Imperial Valley (1979) & 6.5 & El Centro Array\#8 & 0.6 & 0.45 & 0.44 & 0.73 \\
\hline 5 & Cape Mendocino (1992) & 7.0 & Cape Mendocino & 1.5 & 1.04 & 0.75 & 0.50 \\
\hline
\end{tabular}

Table 2: Displacement Demand in Longitudinal Direction

\begin{tabular}{|c|c|c|c|c|c|}
\hline Earthquake & Northridge & Landers & $\begin{array}{c}\text { Loma } \\
\text { Prieta }\end{array}$ & Imperial Valley & $\begin{array}{c}\text { Cape } \\
\text { Mendocino }\end{array}$ \\
\hline Displacement $(\mathrm{mm})$ & 6.88 & 5.66 & 17.07 & 6.45 & $\mathbf{2 1 . 0 2}$ \\
\hline
\end{tabular}

Table 3: Displacement Demand in Transverse Direction

\begin{tabular}{|c|c|c|c|c|c|}
\hline Earthquake & Northridge & Landers & $\begin{array}{c}\text { Loma } \\
\text { Prieta }\end{array}$ & Imperial Valley & $\begin{array}{c}\text { Cape } \\
\text { Mendocino }\end{array}$ \\
\hline Displacement $(\mathrm{mm})$ & 2.4 & 5.66 & 5.10 & 4.5 & $\mathbf{1 4 . 6}$ \\
\hline
\end{tabular}

Fig. 4 and 5 below display typical plot of top displacement in longitudinal and transverse directions under two different time history loadings. 


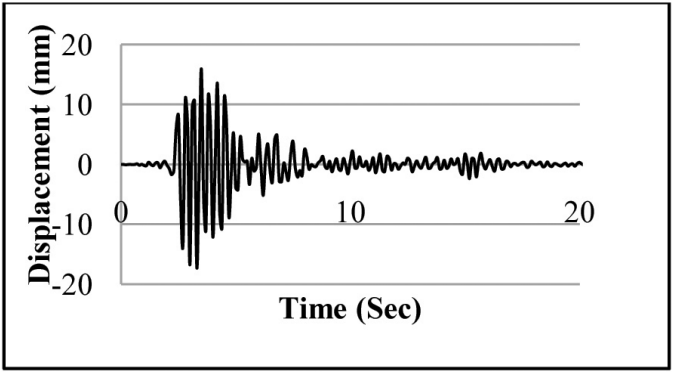

Fig. 4: Typical plot of Top Displacement (mm) in Longitudinal Direction under Loma Prieta TH Loading (PGA 0.644 g)

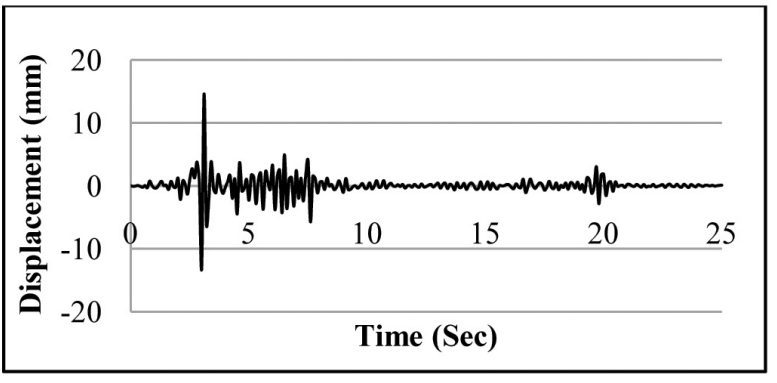

Fig. 5: Typical Plot of Top Displacement $(\mathrm{mm})$ in Transverse Direction under Cape Mendocino TH Loading (PGA 1.04 g)

It was evident from the results of pushover analysis and time history analysis, displacement capacity of the bridge along longitudinal and transverse directions were $60 \mathrm{~mm}$ and $170 \mathrm{~mm}$ respectively and the maximum displacement demand were $21.02 \mathrm{~mm}$ and $14.6 \mathrm{~mm}$ respectively. Thus, the bridge seemed to accommodate the maximum displacement demand in both longitudinal as well as transverse directions.

\section{Application of Horizontal Acceleration Only}

Fig $6 \& 7$ show the peak response displacement and acceleration in both longitudinal and vertical directions when the bridge is subjected to horizontal acceleration only for typical ground motions.

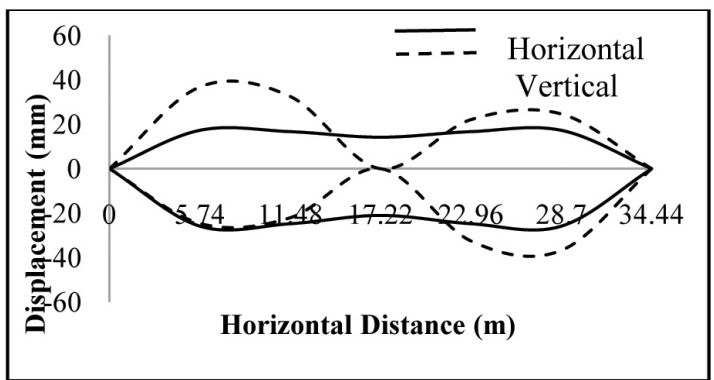

Fig. 6: Peak Displacement of the arch rib when subjected to only horizontal acceleration of Cape Mendocino Ground Motion

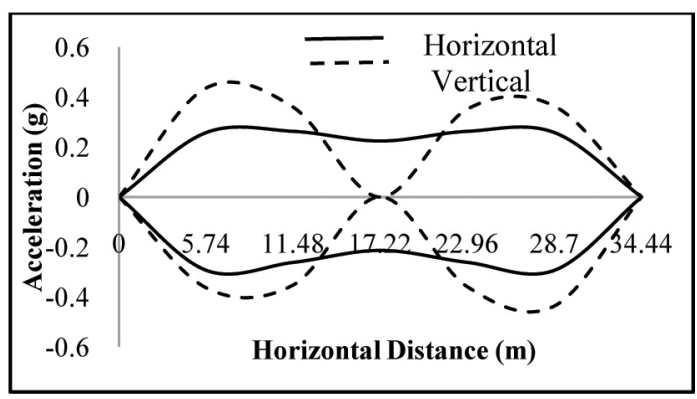

Fig. 7: Peak Response Acceleration of the arch rib when subjected to only horizontal acceleration of Northridge Ground Motion

\section{Application of both Horizontal and Vertical Acceleration}

The vertical ground motion in addition to the horizontal acceleration was then applied to the bridge and compared with the case of horizontal acceleration only. Fig $8 \& 9$ show peak response displacement and acceleration in both longitudinal and vertical directions when the bridge was subjected to horizontal as well as vertical acceleration also. 


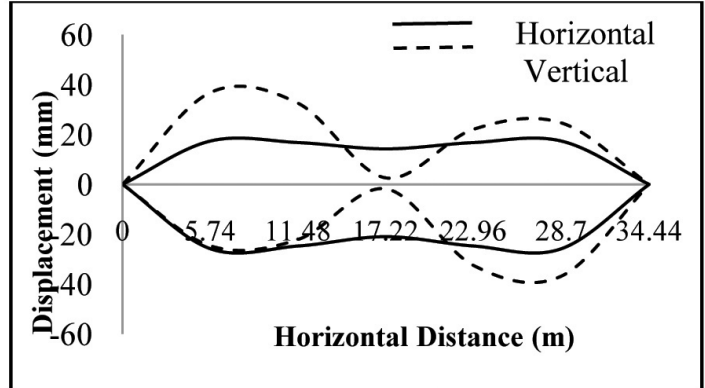

Fig. 8: Peak Displacement of the arch rib when subjected to horizontal as well as vertical acceleration of Cape Mendocino Ground Motion

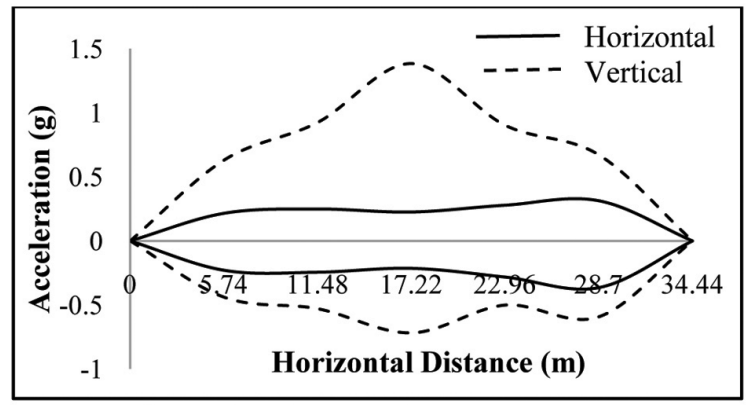

Fig. 9: Peak Response Acceleration of the arch rib when subjected to horizontal as well as vertical acceleration of Northridge Ground Motion

\section{Effect of Vertical Component of Ground Motion}

The effect of vertical acceleration in the arch bridge was studied on the axial force demand on the arch rib. Fig: 10 show the axial force response of the arch rib in the mid section for typical ground motion.

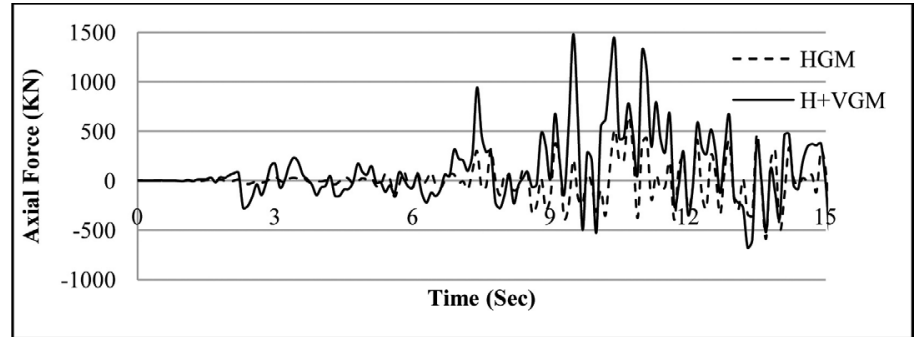

Fig. 10: Axial Force Response of Arch Rib in mid-section for Landers Ground Motion

As shown in Fig: 11, the axial force variation increased considerably when vertical component of different ground motions was taken into account.

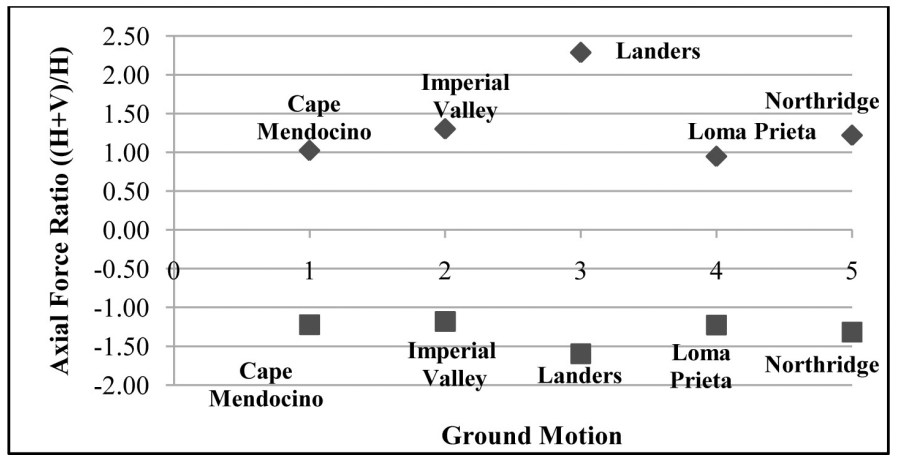

Fig. 11: Axial Force Ratio (Maximum and Minimum) of Arch Rib

Similarly, significant variation was observed in the axial force of spandrel column due to the application of vertical plus horizontal ground motion. Fig 12 shows the effect of vertical ground motion on axial force of the spandrel column (long) for typical ground motion. 


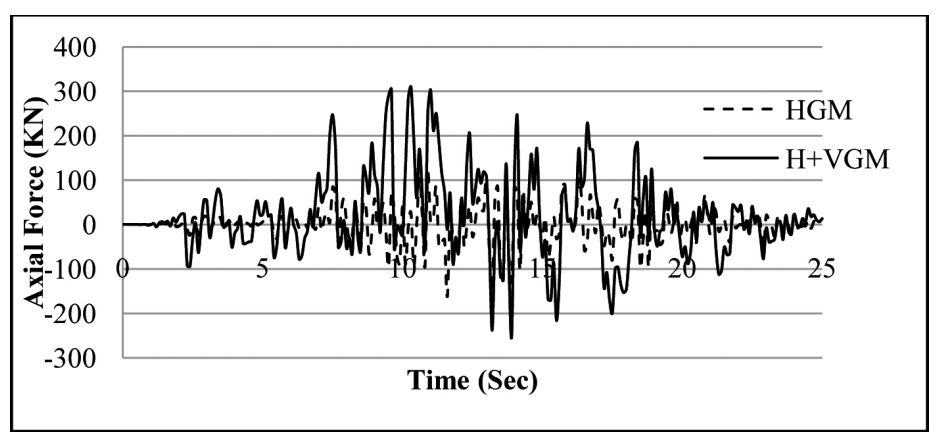

Fig. 12: Axial Force Response of Spandrel Column for Landers Ground Motion

\section{Effect of V/H Peak Ground Acceleration Ratio}

To study the effect of $\mathrm{V} / \mathrm{H}$ peak ground acceleration ratio, $16 \mathrm{~V} / \mathrm{H}$ ratios per earthquake records were considered from 0.5 to 2.0 with an increment of 0.1 for a fixed time interval and horizontal PGA and the results were compared with the case of horizontal acceleration only. The effect of $\mathrm{V} / \mathrm{H}$ ratio on axial force and bending moment of arch rib is presented in Fig. 13 and Fig. 14. It was revealed from the graphs that axial force increased noticeably by up to $350 \%$ due to vertical ground motion component when compared to horizontal ground motion only. Because of high levels of axial force variation due to the inclusion of vertical ground motion, the moment demand also increased significantly.

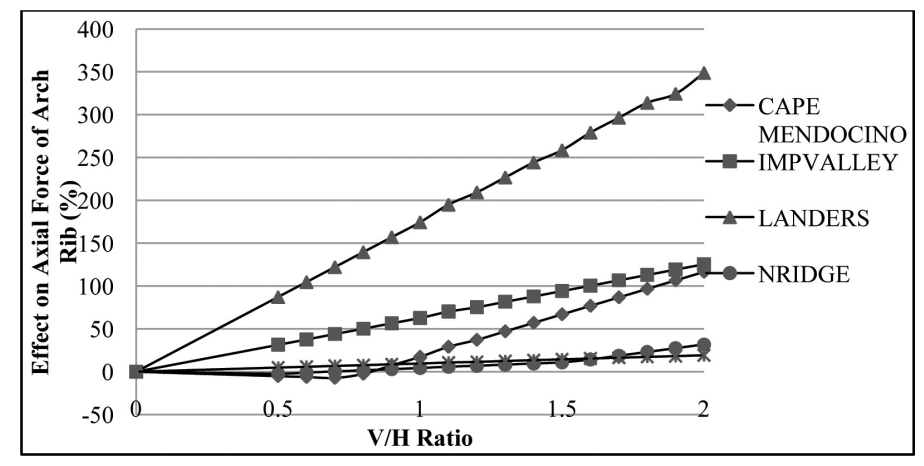

Fig. 13: Effect of V/H Peak Ground Acceleration Ratio on Axial Force of Arch Rib when compared to Horizontal Motion only

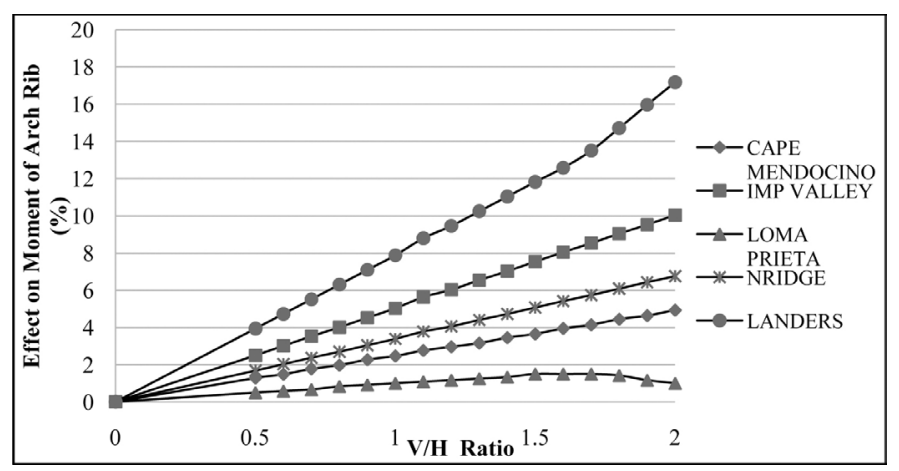

Fig. 14: Effect of V/H Peak Ground Acceleration Ratio on Bending Moment of Arch Rib 


\section{Conclusions}

- Inclusion of vertical component of ground motion has negligible effect in variation of longitudinal displacement. However, there is remarkable effect in axial force variation.

- Response of the bridge increases as $\mathrm{V} / \mathrm{H}$ peak ground acceleration ratio increases. Significant effect in axial force variation in arch rib can be observed as $\mathrm{V} / \mathrm{H}$ ratio increases although the effect in longitudinal displacement with increase in $\mathrm{V} / \mathrm{H}$ ratio is negligible.

- Moment demand also increases due to high axial force variation because of vertical ground motion.

Taking into above considerations, it can be concluded that the bridge subjected to combined horizontal and vertical component of earthquake can be more vulnerable than those subjected to horizontal ground motion only. Therefore, vertical ground motion should be incorporated in the analysis of a reinforced concrete arch bridge.

\section{References}

[1] Chen K and Song JY(2010), Survey and analysis of existing reinforced concrete ribbed arch bridges, Advanced Materials Research, 255-260, 1187-1191.

[2] Kawashima K and Mizoguti A (2000), Seismic response of a reinforced concrete arch bridge, 12WCCE, 1824(1-8).

[3] Kawashima K, Takahashi Y, Ge H, Wu Z and Zhang J (2009), Reconnaissance report on damage of bridges in 2008 Wenchuan China earthquake, Journal of earthquake Engineering, 13: 956998.

[4] Kim SJ, Holub CJ and Elnashai AS (2011), Experimental investigation of the behavior of RC bridge piers subjected to horizontal and vertical earthquake motion, Journal of Engineering Structures, 33(7), 2221-2235

[5] Kosa K, Shi Z, Zhang J and Shimizu H (2011), Damage analysis of Xiaoyudong bridge affected by Wenchuan earthquake China, Journal of Structural Engineering, 57A, 431-441.

[6] Krauss I, Varevac D and Moric D (2010), The Variation of internal forces of the bridge superstructure under influence of the vertical component of the seismic action, Codes in Structural Engineering, 823-830.

[7] Rahai A and Arezoumandi M (2008), Effect of vertical motion of earthquake on RC bridge pier. The $14^{\text {th }}$ World Conference on Earthquake Engineering. 